\title{
Optimized Tin Bismuth Alloy Modified with Silver Vanadate Nanorods Prepared via Powder Metallurgy: Search for Biomedical Application
}

\author{
Raghda Abou Gabal ${ }^{1 *}{ }^{(\mathbb{D})}$, Rizk Moustafa Shalaby ${ }^{2}{ }^{(\mathbb{D})}$, Mustafa Kamal ${ }^{2(\mathbb{D})}$, Amr. Abdelghany ${ }^{3(\mathbb{D}}$ \\ Mansoura Urology and Nephrology Center, Mansoura University, Mansoura, 35516, Egypt \\ Physics Department, Faculty of Science, Mansoura University, Mansoura, 35516, Egypt \\ Spectroscopy Department, Physics Division, National Research Center, 33 Elbehouth St., Dokki, 12311, Cairo, Egypt \\ * Correspondence: raghdaabogabal@gmail.com;
}

Scopus Author ID 57211375196

Received: 2.08.2020; Revised: 15.08.2020; Accepted: 17.08.2020; Published: 19.08.2020

\begin{abstract}
In this study, a new bismuth tin eutectic alloy and other samples of the same composition doped with variable concentration of silver vanadate nanorods were prepared using new route powder metallurgy. X-ray diffraction of prepared silver vanadate approves the formation of $\beta$ phase silver vanadate $\left(\beta-\mathrm{AgVO}_{3}\right)$. Transmission electron microscopy shows the formation of $\mathrm{AgVO}_{3}$ nanorods of radius ranging (20-40 $\mathrm{nm})$. X-ray diffraction of alloys doped with silver vanadate and mechanical tests show that hardness and creep behavior data are composition-dependent parameters with silver vanadate content. Antimicrobial tests against pathogenic grams, fungi, and yeast showed that the addition of silver vanadate nanorods stimulates the action of hydride alloy and increases their activity against bacterial strains. In hospitals, biomedical devices may contaminate infection; doping devices with nanoparticles may make it auto clean besides conserving its mechanical properties.
\end{abstract}

Keywords: Powder metallurgy; eutectic alloy; Silver vanadate; Antibacterial test.

(C) 2020 by the authors. This article is an open-access article distributed under the terms and conditions of the Creative Commons Attribution (CC BY) license (https://creativecommons.org/licenses/by/4.0/).

\section{Introduction}

In the development of new materials based on biomedical applications, the tailoring of the structure is a very important method to produce useful biomaterials. The tin-bismuth eutectic system has attracted attention in recent times as it has potential application as antibacterial activity in the biomedical application [1,2]. Bismuth compounds are safe as they are used as medicines for the treatment of gastrointestinal ailments and gastroprotective in treating $\mathrm{H}$. pylori infection in addition to their broad antimicrobial, anti-cancer, and antileishmanial properties $[3,4]$. The ideal biomedical materials in our concern should possess excellent tribological properties. To achieve those properties, materials physicists and engineers have devoted considerable efforts [5].

The eutectic temperature of $\mathrm{Bi}-\mathrm{Sn}$ is a simple eutectic, consisting of Tin and bismuth terminal solid solutions reported by Ohtani, and Ishida [6] was found to be $138 \mathrm{C}^{\circ}$. The solubility of $\mathrm{Bi}$ in $\mathrm{Bi}-\mathrm{Sn}$ is $21 \%$ at the eutectic temperature and decreases to about $2 \%$ at room temperature. The maximum solubility of $\mathrm{Sn}$ in $\mathrm{Bi}$ is $1 \%$.

Siddhartha Shrivastava [7] et al. note the development of silver nanoparticles in size of $10-15 \mathrm{~nm}$ with increased stability and enhanced antibacterial potency. Even though bacterial cell damage would be the main reason for the antibacterial property, it is also suggested that 
nanoparticles also vary the phosphotyrosine profile of supposed bacterial peptides, which inhibit the growth of the organisms.

Doping endodontic sealers with nanoparticles to optimize antimicrobial activity with interaction at a molecular level. The nanostructured silver vanadate decorated with silver nanoparticles $\left(\mathrm{AgVO}_{3}\right)$ is a nanomaterial unprecedented in dentistry for this application [8]. In recent times the requirement for unusual combinations of multicomponent materials to be used for particular purposes with a tailored characteristic is the motivation of scientists and academia. The ease of processing, cost, and power consumption are the major issues that are being considered in the manufacturing process [9]. The addition of nanostructured materials to metallic alloys was expected to give a notable change in their characteristics depending on their shape (rods, spheres, and stars), distribution, and size [10].

In this paper, hydride eutectic alloy of $\mathrm{Bi}-\mathrm{Sn}$ doped with $\mathrm{AgVO}_{3}$ nanorods synthesized using powder compaction at ordinary room temperature was reported for the first time. Structural, mechanical, and antimicrobial behavior of such alloys were studied and correlated to their structure.

\section{Materials and Methods}

Samples of nominal composition $x \mathrm{AgVO}_{3}-(100-x)\left[\mathrm{Sn}_{43} \%-\mathrm{Bi} 57 \%\right]$ see Table 1 prepared from analytical grade chemicals. Tin powder supplied by WINLAB UK fine chemicals, Bismuth powder 100 mesh supplied by Aldrich Chemical Company, ammonium vanadate $\left(\mathrm{NH}_{4} \mathrm{VO}_{3}\right)$, and $\left(\mathrm{AgNO}_{3}\right)$ supplied by Sigma Aldrich Co.

Table 1. Sample composition and hardness measurements.

\begin{tabular}{l|c|c|c}
\multirow{2}{*}{ Sample } & \multicolumn{3}{|c}{$\boldsymbol{x}$ AgVO3-(100- $\boldsymbol{x})\left[\mathbf{S n}_{\mathbf{4 3} \%}-\mathbf{B i}_{\mathbf{5} 7 \%} \mathbf{]}\right.$} \\
\cline { 2 - 4 } & $\mathbf{S n}$ & $\mathbf{B i}$ & $\mathbf{A g O O}_{\mathbf{3}}$ \\
\hline S0 & 43.00 & 57.00 & 0.00 \\
\hline S1 & 42.57 & 56.43 & 1.00 \\
\hline S3 & 41.71 & 55.29 & 3.00 \\
\hline S5 & 40.85 & 54.15 & 5.00 \\
\hline S7 & 39.99 & 53.01 & 7.00
\end{tabular}

\subsection{Preparation of silver vanadate nano rods.}

$100 \mathrm{ml}$ of equal concentrations $(0.005 \mathrm{M})$ of both ammonium vanadate $\left(\mathrm{NH}_{4} \mathrm{VO}_{3}\right)$ and silver nitrate $\left(\mathrm{AgNO}_{3}\right)$ were prepared in deionized water. The prepared solution of $\left(\mathrm{AgNO}_{3}\right)$ was added and mixed vigorously using the magnetic stirrer to a solution of $\left(\mathrm{NH}_{4} \mathrm{VO}_{3}\right)$ drop by drop at room temperature and fixed $\mathrm{pH}(\sim 4.6)$. During the fraternization process $\mathrm{pH}$ of the product varies between 4.6 up to 5.8, and the dark yellow colored precipitate was synthesized with a final $\mathrm{pH}$ of about 5.8(de Melo Monteiro). The final product was examined using different characterization routes, including X-ray diffractometry (XRD) transmission and scanning electron microscopy (TEM, SEM) [11].

\subsection{Preparation of metallic alloys (powder compaction).}

Pre-calculated weights of metal powder were mixed thoroughly for about $10 \mathrm{~min}$ to ensure the homogeneity of the prepared samples before compaction. One gram of metal powder from each composition was subjected to high pressures $\left(10 \mathrm{ton} / \mathrm{cm}^{2}\right)$ in a cylindrical compression die of diameter $1 \mathrm{~cm}$. Compressed samples were ejected from the die cavity and 
stored in a vacuum desiccator until use. Three samples from each composition were used for each measurement. The sample composition and nominations are listed in Table 1.

\subsection{Characterization techniques.}

\subsubsection{X-ray diffraction.}

The structure of samples was assessed using an X-ray powder diffractometer Philips PANalytical X'Pert XRD System, adopting a Ni-filter and a Cu-target of $(\lambda=1.54056 \AA$ operated with $4.5 \mathrm{kV}$ and $35 \mathrm{~mA}$ ) within a diffraction angle ranging between $5-80^{\circ}$ with a scan rate $5 \mathrm{deg} / \mathrm{min}$. Lattice parameters of the phases were calculated with the Williamson-Hall approach equation $[12,13]$.

\subsubsection{Density and microhardness.}

The sample density was measured using the Archimedes method, water as fluent liquid, Metler Toledo four-digit balances. Measurement was done for triplicate samples, and the average value was plotted against $\mathrm{AgVO}_{3}$ content.

Microhardness test of the newly synthesized alloys was performed for triplicate samples via (FM-7 Japan) digital Vickers microhardness tester using 60g constant load for 5 seconds. At least 20 indentations were performed and averaged to calculate mean hardness values. The applied load was chosen to give adequately small restrain any affinity for cracking, which can partially alter the hardness measurements [14].

\subsubsection{Micro-creep.}

Creep is a time-dependent permanent deformation that takes place after a hard indentor penetration into the material under a constant load for a long time at a constant temperature. The variation in the indentation size, either variation in time with a diameter (Brinell test) or diagonal length (Vickers hardness), is expressed with dwell time. Thus, the time-dependent flow behavior of materials can be studied by these simple hardness tests; the indentation creep tests, regarded as a quick, simple, and non-destructive to get information about the mechanical behavior of materials and reduce the effort in sample preparation [15].

\subsubsection{Bioactivity and antimicrobial activity tests.}

The agar plate route has been implemented for the antimicrobial activities examination of synthesized nanostructured alloy samples previously reported by R.Abou Gabal et al. [5]. Gram-positive pathogenic bacteria (Staphylococcus aureus), Gram-negative pathogenic bacteria (Escherichia coli), were selected to appraise the antimicrobial activity of different chosen grams against different samples. The culture of all tested microbe was diluted using sterilized bi-distilled water. Studied samples in discs form superficially placed on agar plates seeded with test microbes and incubated at $37^{\circ} \mathrm{C}$ for about $24 \mathrm{~h}$ and recorded as the clear zone diameter including sample itself $[16,17]$. 


\section{Results and Discussion}

\subsection{Characterization of prepared silver vanadate.}

Figure 1 reveals a typical x-ray diffraction pattern (XRD) of the synthesized $\mathrm{AgVO}_{3}$ nanostructured material prepared using a chemical precipitation method at room temperature. Obtained data assigned to the presence of both $\alpha$ and $\beta-\mathrm{AgVO}_{3}$ without any evidence for the presence of any other phases or remained residuals of silver and supported by the previously published data indexed using JCPDS cards. Notified diffraction peaks can be indexed to the $\beta$ $\mathrm{AgVO}_{3}$ phase (JCPDS 29-1154) that constitute the main phase in addition to the $\alpha-\mathrm{AgVO}_{3}$ phase(JCPDS 19-1151) with relatively very low diffraction peaks compared with that of $\beta$ phase.

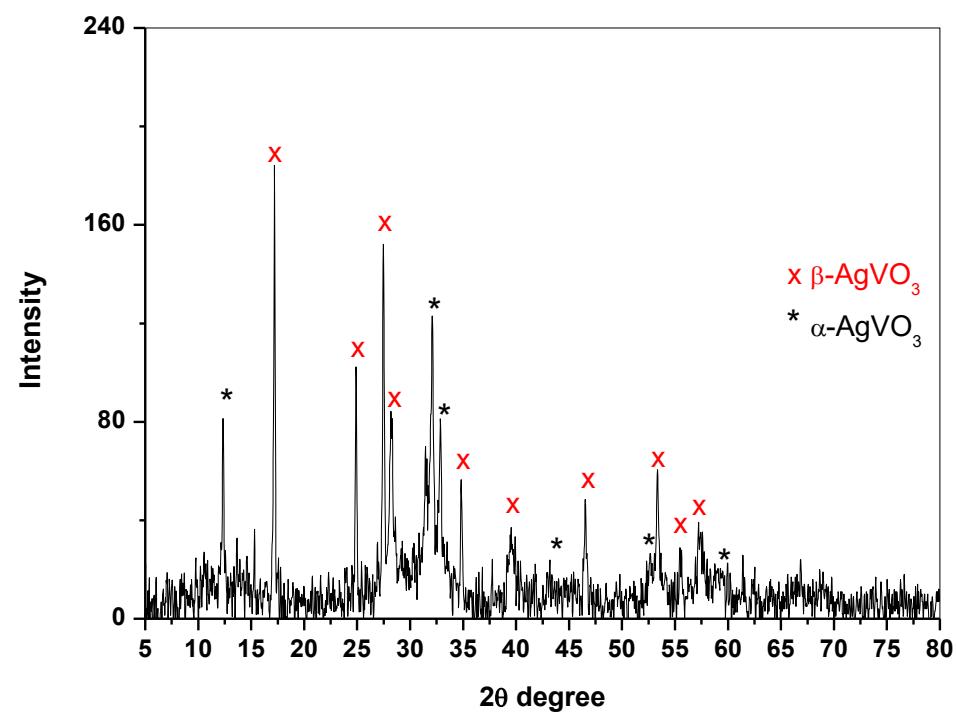

Figure 1. X-ray diffraction pattern of prepared silver vanadate.

SEM results Figure 2 shows the presence of high yield with homogeneous nanorods distribution within the synthesized material while transmission electron micrographs (TEM) Figure 3 reveals the formation of well-defined $\mathrm{AgVO}_{3}$ nanorods with diameters ranging between 20:40 $\mathrm{nm}$ and length of about $1 \mu \mathrm{m}$ without any evidence for the formation of any structure rather than rods.

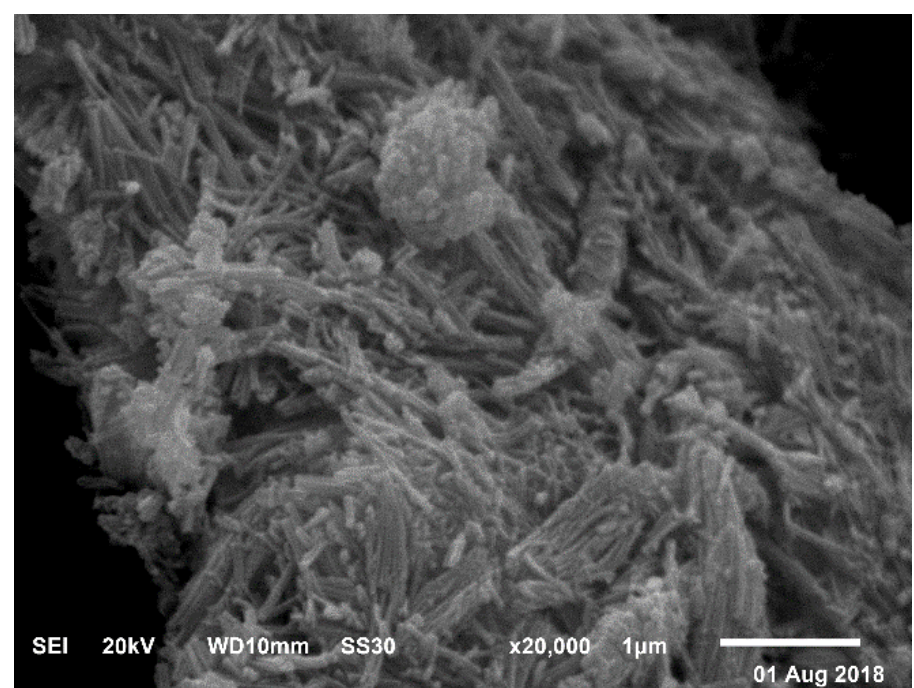

Figure 2. SEM image of prepared silver vanadate. 


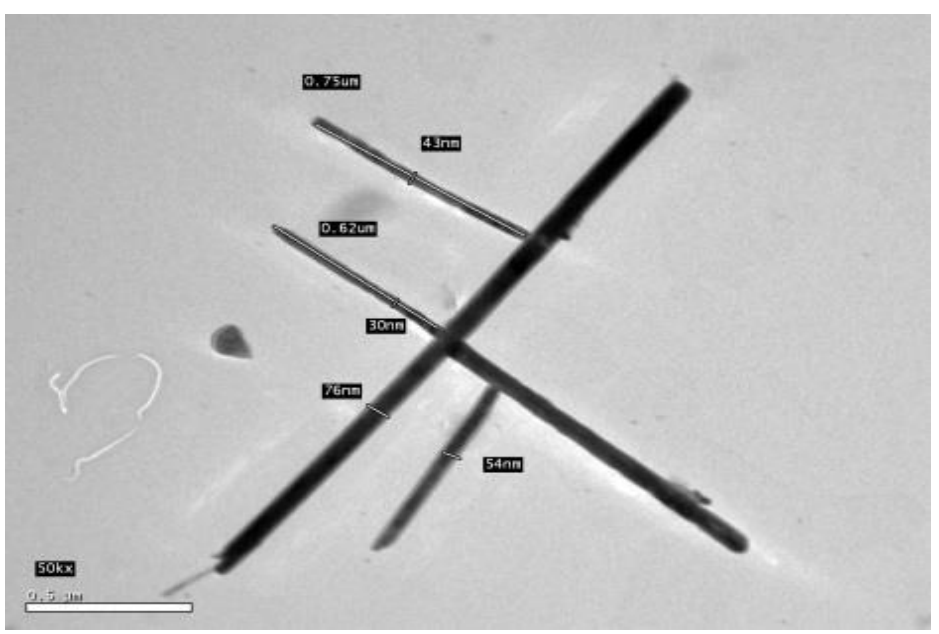

Figure 3. TEM image of prepared silver vanadate.

\subsection{X-ray diffraction of prepared metal nano-structure.}

\subsubsection{Phase composition.}

The diffraction line broadening study from the samples under study may give important information. The line broadening has been observed to be caused mainly by the small particle size or by the strains, which have been caused or observed to increase with increasing $\mathrm{AgVO}_{3}$ concentration, so in the present investigation, the broadening was observed to be caused by the small particle size, and the strains.

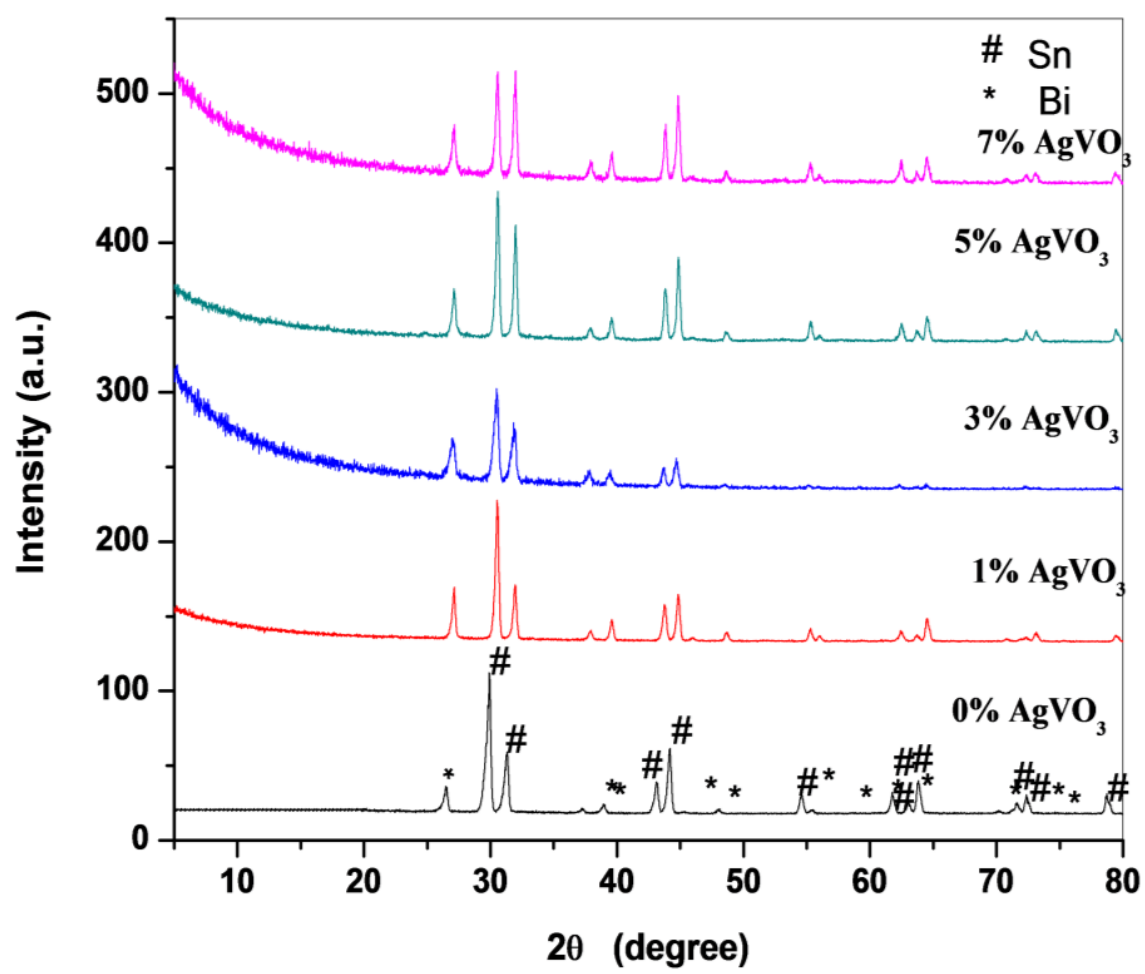

Figure 4. X-ray diffraction of metallic alloys doped with silver vanadate nanorods.

Figure 4 shows the x-ray diffraction pattern of different synthesized samples. It is clear that prominent diffraction peaks attributed to the eutectic Sn-Bi alloy as a control sample were present nearly in all samples, which are varied with the addition of variable content of synthesized $\mathrm{AgVO}_{3}$. 


\subsubsection{Lattice parameters.}

The structure of Sn-phase can be indexed in terms of a tetragonal structure similar to the $\beta$-Sn structure. A considerable shift in the lattice parameters from the equilibrium value can be observed. The lattice parameters a and c obtained from the analysis of the diffraction patterns which have values that can be compared with lattice parameters of equilibriums of Sn (a $=5.83 \mathrm{~A}^{\circ}$ and $\left.\mathrm{c}=3.18 \mathrm{~A}^{\circ}\right)$ and $\mathrm{Bi}(\mathrm{a}=4.546, \mathrm{c}=11.86)$ listed in Table 2 . The numbers of atoms related to both $\mathrm{Bi}$ and $\mathrm{Sn}$ are calculated and listed in Table 3. Where, Tetragonal lattice parameter of Sn and Rhombohedra lattice parameter of Bi can be calculated using the equations $(1,2)$ respectively $[18]$;

$$
\begin{gathered}
\frac{1}{d^{2}}=\frac{\left(h^{2}+k^{2}\right)}{a^{2}}+\frac{l^{2}}{c^{2}} \\
\frac{1}{d^{2}}=\frac{\left[\left(h^{2}+k^{2}+l^{2}\right) \sin 2 \alpha+2(h k+k l+h l)(\cos 2 \alpha)\right]}{a^{2}(1-3 \cos 2 \alpha+2 \cos 3 \alpha)}
\end{gathered}
$$

\begin{tabular}{|c|c|c|c|c|c|c|c|c|}
\hline \multirow{2}{*}{$\mathrm{AgVO}_{3}$ Content } & \multicolumn{4}{|c|}{ Bi Rhomobohedral Phase } & \multicolumn{4}{|c|}{ Sn tetragonal phase } \\
\hline & aRoh & $\mathrm{C}$ & $\mathrm{C} / \mathrm{a}$ & $\mathrm{V} \mathbf{A}^{\mathbf{0 3}}$ & $\mathbf{a} \mathbf{A}^{0}$ & $\mathrm{CA}^{0}$ & $\mathrm{C} / \mathrm{a}$ & v $\mathbf{A}^{\mathbf{0 3}}$ \\
\hline $1 \% \mathrm{AgVO}_{3}$ & 4.83 & 12.20 & 2.699 & 71.77 & 5.83 & 3.21 & 0.546 & 109.00 \\
\hline $3 \% \mathrm{AgVO}_{3}$ & 4.66 & 11.53 & 2.520 & 69.40 & 5.84 & 3.22 & 0.550 & 109.68 \\
\hline $5 \% \mathrm{AgVO}_{3}$ & 4.75 & 11.80 & 2.500 & 71.84 & 5.80 & 3.10 & 0.530 & 102.08 \\
\hline $7 \% \mathrm{AgVO}_{3}$ & 4.69 & 11.60 & 2.500 & 70.94 & 5.84 & 3.18 & 0.544 & 108.60 \\
\hline
\end{tabular}

Table 2. Lattice parameters of studied samples.

The number of an atom in the unit cell can be calculated from identified phases, the volume of a unit cell, and calculated lattice parameters using equation (3-5).

The volume of the unit cell:

$$
\Sigma \mathrm{A}=\frac{\rho v}{1.66020}=n A
$$

Tetragonal

$$
V=a^{2} \mathrm{c}
$$

Rhombohedral

$$
V=a^{3} \sqrt{(1-3) \operatorname{Cos}^{2} \alpha+2 \operatorname{Cos}^{3} \alpha}+
$$

Where

$\Sigma \mathrm{A}$ is the sum of the atomic weights of the atoms in the unit cell

$\rho$ is the density $\left(\mathrm{gm} / \mathrm{cm}^{3}\right)$

$\mathrm{v}$ is the volume of the unit cell

Table 3. Number of atoms related to both $\mathrm{Bi}$ and $\mathrm{Sn}$.

\begin{tabular}{l|c|c}
\multirow{2}{*}{$\mathrm{AgVO}_{3}$ Content } & \multicolumn{2}{|c}{ No. of atoms } \\
\cline { 2 - 3 } & Bi Rhomobohedral Phase & Sn tetragonal phase \\
\hline $1 \% \mathrm{AgVO}_{3}$ & $\mathbf{2 . 0 0}$ & $\mathbf{4 . 0 3}$ \\
\hline $3 \% \mathrm{AgVO}_{3}$ & $\mathbf{2 . 0 0}$ & $\mathbf{4 . 0 2}$ \\
\hline $5 \% \mathrm{AgVO}_{3}$ & $\mathbf{1 . 9 9}$ & $\mathbf{4 . 0 2}$ \\
\hline $7 \% \mathrm{AgVO}_{3}$ & $\mathbf{2 . 0 0}$ & $\mathbf{4 . 0 2}$
\end{tabular}

\subsubsection{Structural data.}

The microstructural analysis using a scanning electron microscope shows evidence of homogenous structure with a smooth surface without any evidence for phase separation or contamination. Figure 5. shows the SEM micrographs for the synthesized nanostructured eutectic alloy samples that contain different percentages of silver nanorods. 


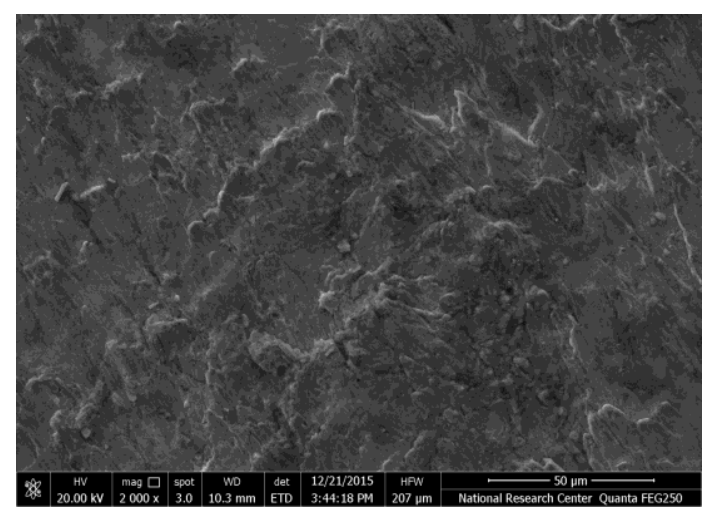

$1 \% \mathrm{AgVO}_{3}$

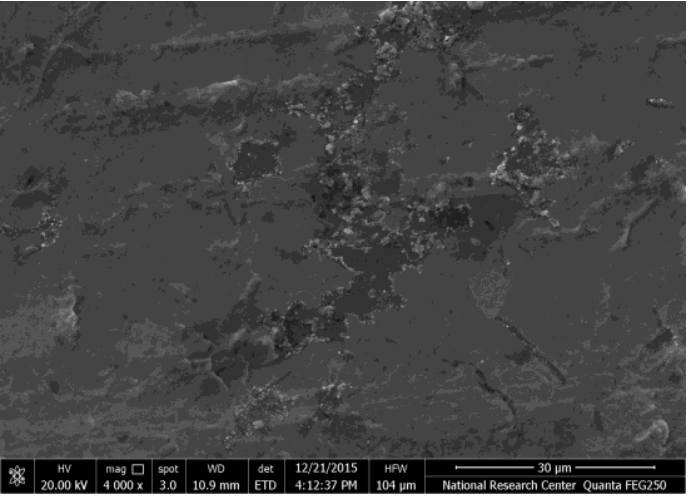

$5 \% \mathrm{AgVO}_{3}$

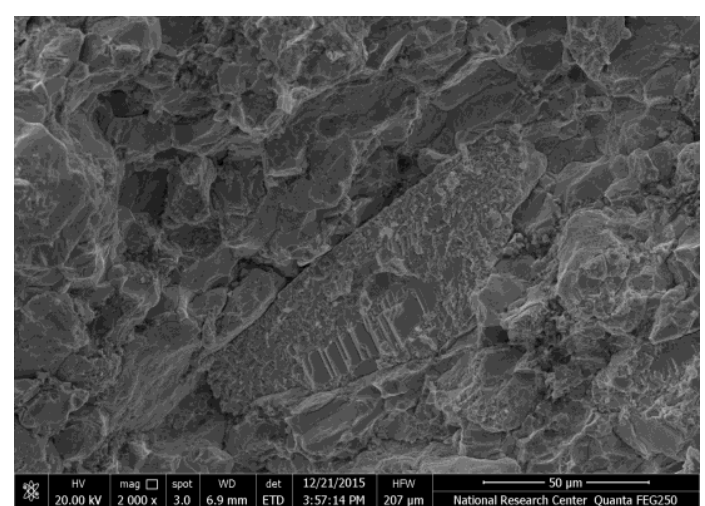

$3 \% \mathrm{AgVO}_{3}$

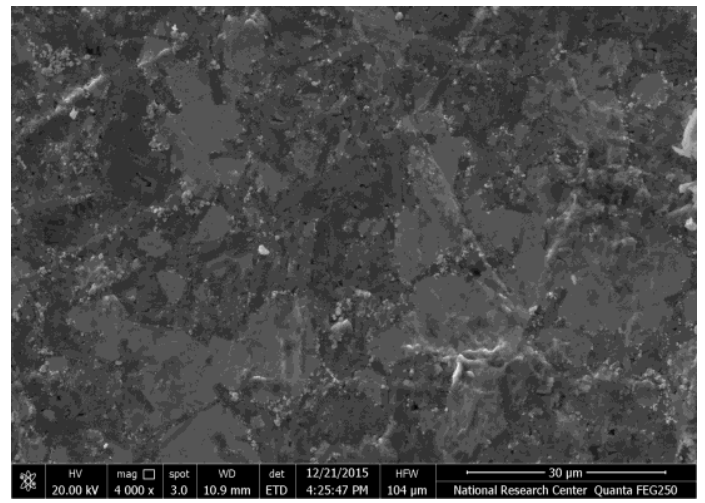

$7 \% \mathrm{AgVO}_{3}$

Figure 5. SEM micrograph of prepared metal nano-structure.

\subsubsection{Lattice disorder.}

Calculated particle size and lattice distortion for all studied samples are shown in Table 4. Obtained data for Bi in the Rhomobohedral phase shows a smooth increasing behavior of both particle size and lattice distortion result from the gradual addition of silver nanorods incomparable with the Sn tetragonal phase suggesting the notable effect of lamellar structure and interaction resulting from gradual increase of the Silver vanadate nanorods content [19].

Table 4. Particle size and lattice distortion for all studied samples.

\begin{tabular}{l|c|c|c|c}
\multirow{2}{*}{ AgVO $_{3}$ Content } & \multicolumn{2}{|c|}{ Bi Rhomobohedral Phase } & \multicolumn{2}{c}{ Sn tetragonal phase } \\
\cline { 2 - 4 } & Particle size & Lattice distortion & Particle size & Lattice distortion \\
\hline $1 \% \mathrm{AgVO}_{3}$ & 335.1937 & 0.001200 & 306.0159 & 0.001341 \\
\hline $3 \% \mathrm{AgVO}_{3}$ & 384.9623 & 0.001605 & 571.4294 & 0.001181 \\
\hline $5 \% \mathrm{AgVO}_{3}$ & 568.7593 & 0.001057 & 360.3787 & 0.00124 \\
\hline $7 \% \mathrm{AgVO}_{3}$ & 315.2795 & 0.001431 & 369.0001 & 0.001179
\end{tabular}

3.2.5. Crystallite size and lattice strain.

The crystallite size of samples was determined using XRD patterns and WilliamsonHall approach equation [20].

\subsection{Density and hardness measurements.}

Hardness testing provides valuable information concerning the mechanical behavior of solids [16-18]. Indentation measurements have been applied to a wide range of materials. Presently there is a growing interest in probing biological materials. So the aim of this section to introduce a better understanding of instrumented indentation measurements in the field for biomedical materials[21]. A load of $(60 \mathrm{~N})$ was applied to each sample for 5 seconds, and the 
measurement repeated about ten times for each sample separately as indicated in Table 5.and the values were calculated using the standard Vickers formula:

$$
H_{v}=\frac{1.8544(P)}{d^{2}}
$$

Where $\mathrm{P}$ is the indentation force, $\mathrm{d}$ is the average diagonal length, and 1.8544 is a constant of a geometrical factor for the pyramid.

It was noted that microhardness values for samples by adding $\mathrm{AgVO}_{3}$ to the base alloy, the hardness values rose to 35.6. The mechanical properties were determined by Vickers microhardness as performed on preceding literature studies [16-18]. This increase can be interpreted as an indication that the hardness of samples is a function of total solute concentration. Furthermore, it can be also be seen from Figure 6 that the microhardness of the samples is approximately higher than those of the original alloy. The atomic radius difference between elements in solid solution provides a strain yield.

Figure 6 shows the relation between both density and Vicker Microhardness value to the silver vanadate content (wt\%). It was found that density decreases with increasing $\mathrm{AgVO}_{3}$ content. At the same time, the values of microhardness were found to be increased with increasing silver vanadate content. Such an increase may be attributed to the formation of the lamellar structure resulting from the nature or shape of synthesized silver vanadate.

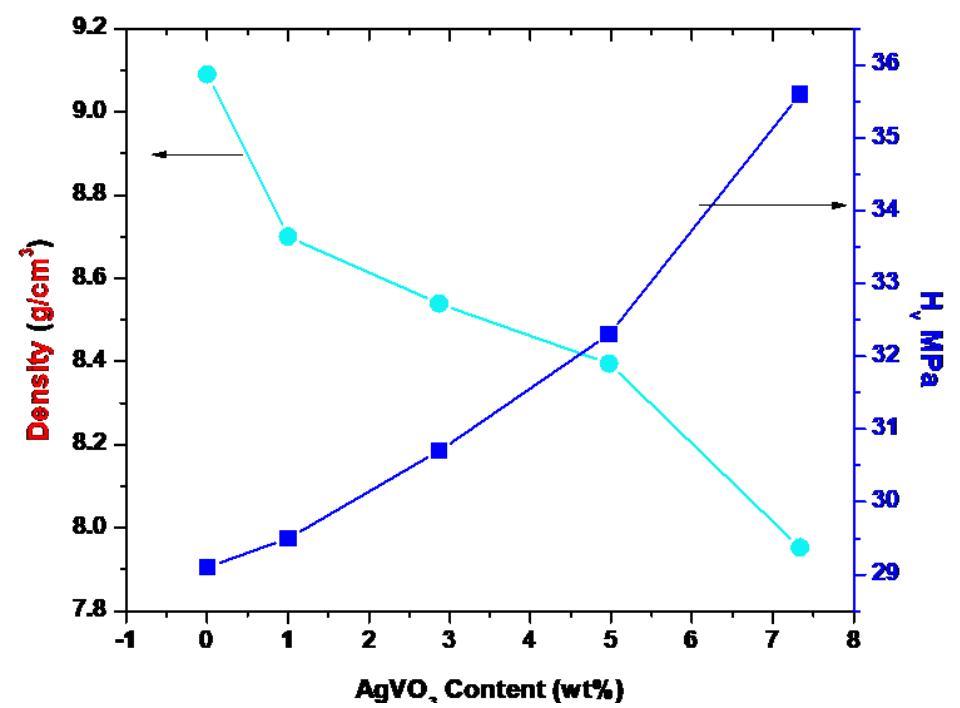

Figure 6. Relation between density, hardness, and silver vanadate content.

Table 5. Vicker hardness and density of prepared samples.

\begin{tabular}{l|c|c} 
Sample & $\mathbf{H}_{\mathbf{v}}(\mathbf{M P a})$ & Density $\left(\mathbf{g m} / \mathbf{c m}^{\mathbf{3}}\right)$ \\
\hline $\mathrm{S} 0$ & $29.10 \pm 0.68$ & 9.1 \\
\hline $\mathrm{S}_{1}$ & $29.50 \pm 0.88$ & 8.7 \\
\hline $\mathrm{S}_{2}$ & $30.70 \pm 0.92$ & 8.6 \\
\hline $\mathrm{S}_{3}$ & $32.30 \pm 0.97$ & 8.5 \\
\hline $\mathrm{S}_{4}$ & $35.60 \pm 1.07$ & 7.9
\end{tabular}

\subsection{Creep.}

For control, sample $\mathrm{H}_{\mathrm{v}}$ has the lowest value of $30.3 \mathrm{MPa}$ that decreased ascendingly until it reaches $19.3 \mathrm{MPa}$ after $90 \mathrm{~s}$ in Fig 7. For $\mathrm{S} 9 \mathrm{H}_{\mathrm{v}}$ has the highest value $44.5 \mathrm{MPa}$, then it drops at a constant rate to $37.2 \mathrm{MPa}$ for $90 \mathrm{~s}$ of indentation time. Therefore, creep is the increase in the area (strain) with the indentation time under constant load. The strain is measured as the fractional change in the area and is given by the strain $=\Delta \mathrm{S} / \mathrm{So} \%$, where $\Delta \mathrm{S}=\mathrm{S}$-So, and So is the strain (area) at the minimum indentation time. The estimation of creep in this way is called 
"microcreep"; the term microcreep comes from applying the stress to a very tiny area in comparison to the area of grain, and it is noticed by a microscope. As given above, plotting the strain with indentation time, a characteristic creep curve obtained, as shown in Fig 8. The figure shows the variation of local strain with indentation time through interval 0 to $99 \mathrm{~s}$ of eutectic Sn-Bi alloys. The behavior of alloys has two stages, namely as primary and secondary creep stages. The first stage starts from the beginning to about $40 \mathrm{~s}$ followed by the second stage up to $99 \mathrm{~s}$. This second stage is called the steady-state region in which the strain increases linearly with indentation time. The third stage of normal creep is not occurring since it is impossible because this method is a compression method. From the steady-state region, the creep rate of the alloy can be calculated.

It is shown that the control sample has the lowest creep rate than other samples. Also, the creep rate decreases continuously with increasing $\mathrm{AgVO}_{3}$ nano-rods content. This behavior can be revealed to the change of a solid solution of both $\mathrm{Sn}$ and $\mathrm{Bi}$.

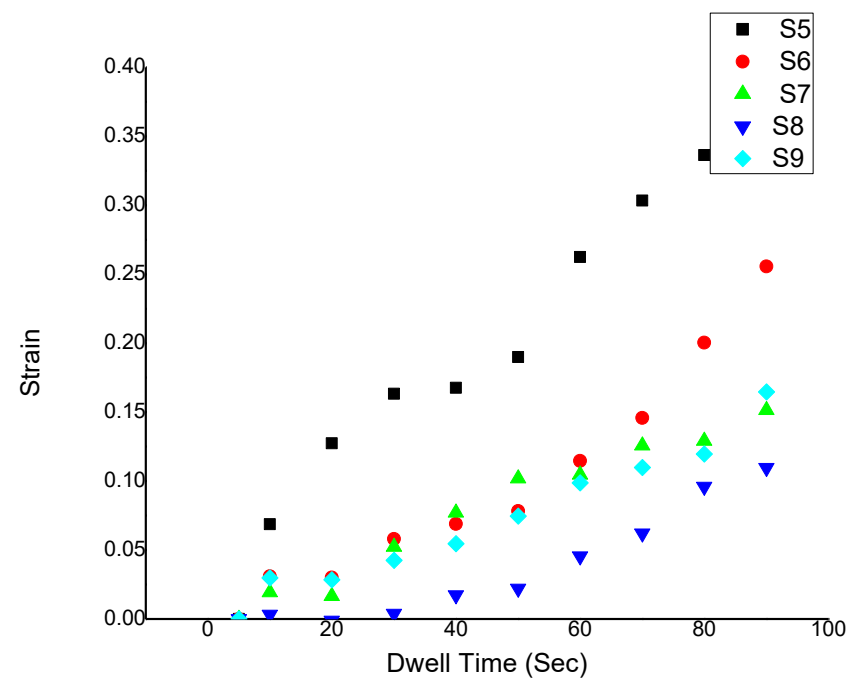

Figure 7. The deviation of $\mathrm{H}_{\mathrm{v}}$ with dwell time.

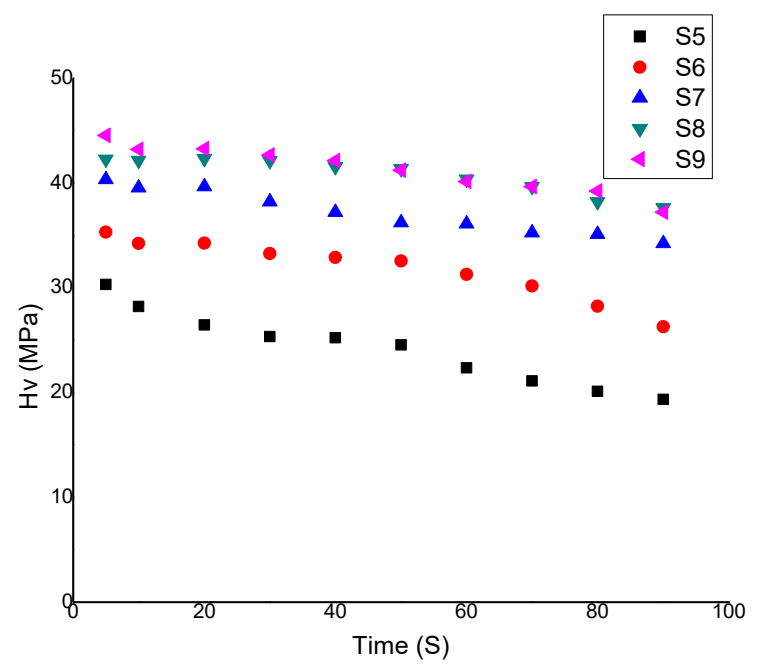

Figure 8. The creep behavior of eutectic (Sn43\%-Bi57\%) alloy containing a different mass fraction of silver vanadate. 


\subsection{Antibacterial results.}

The results indicated that eutectic alloys have a significant effect on Gram (-) more than Gram (+) as in Fig 9. that may be due to the positive charges of the substrate surface, there is a universal characteristic of electric charge properties of biofilms regardless of the kind of substrate. Many types of research refer that all bacteria biofilm have negative $\zeta$ potential, but biofilm formed after the adhesion of bacteria with the surface, so we may conclude that cell wall type also plays an essential role like electrostatic force.

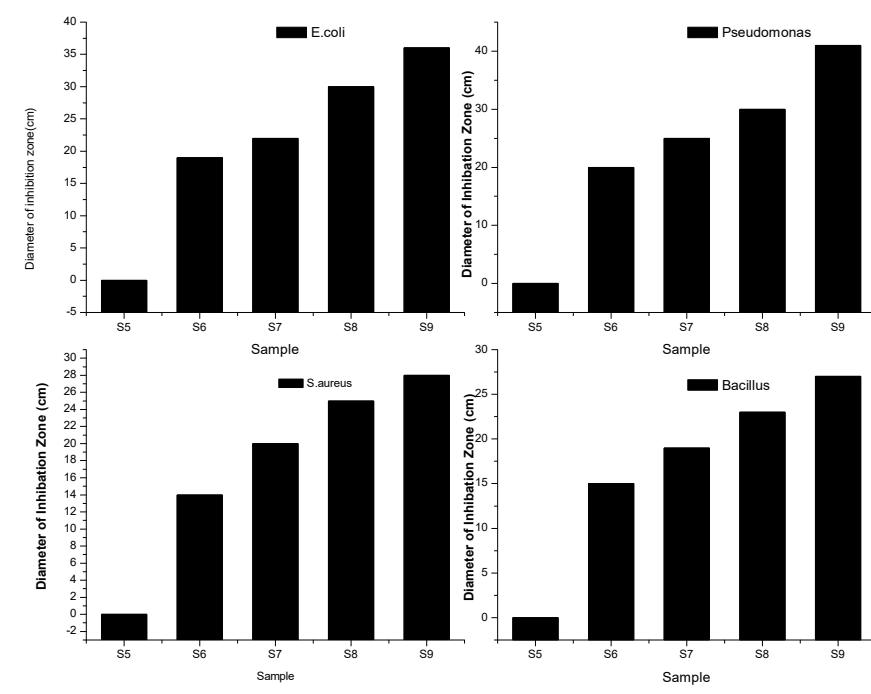

Figure 9. MIZ versus Tin-Bismuth alloys [ $\left.\mathrm{Sn}_{43 \%}-\mathrm{Bi}_{57 \%}\right]$ eutectic alloys are containing a different mass fraction of silver vanadate for a different pathogenic bacteria eutectic.

\section{Conclusions}

Silver vanadate nanorods were successfully synthesized using traditional chemical precipitation method at room temperature. Synthesized nanoparticles were characterized through SEM, TEM, and XRD. All measurements approve the formation of $\alpha$ and $\beta$ phases of silver vanadate nanorods (20-40 $\mathrm{nm}$ diameter, $1 \mu \mathrm{m}$ length) without any evidence for the formation of other phases. Hydride eutectic Sn-Bi alloys containing a different mass fraction of synthesized silver vanadate nanorods were then prepared via cold compaction technique.

Structural and mechanical properties were found to be composition dependent parameters with silver vanadate content assigned to the formation of the lamellar structure resulting from the addition of silver vanadate nanorods. Creep behavior is decreased by doping nanorods that mean little deformation that take place after a hard indentor penetration into the material under a constant load. This behavior may result from the lamellar structure of nanorods.

Antimicrobial tests against pathogenic grams showed that the addition of silver vanadate nanorods stimulates the action of hydride alloy and increases their activity against bacterial strains besides conservation with physical and mechanical properties of the alloy.

\section{Funding}

This research received no external funding. 


\section{Acknowledgments}

This research has no acknowledgment.

\section{Conflicts of Interest}

The authors declare no conflict of interest.

\section{References}

1. Lemire, J. A.; Harrison, J. J.; Turner, R. J. Antimicrobial activity of metals: mechanisms, molecular targets and applications. Nature Reviews Microbiology 2013, 11(6), 371-384., https://doi.org/10.1038/nrmicro3028.

2. Kamal, M.; Abogabil, R.; Al-Wakeel, E. E.; MM, A. E. R.; Shalabi, K.The Physical and Biological Properties of Alkali-Heat Treated Titanium Implant Material. IJET-IJENS 2013, 13(04).

3. Keogan, D. M.; Griffith, D. M. Current and potential applications of bismuth-based drugs. Molecules 2014, 19(9), 15258-15297. https://doi.org/10.3390/molecules190915258.

4. Javadhesari, S.M.; S. Alipour.; M. R. Akbarpour. "Biocompatibility, osseointegration, antibacterial and mechanical properties of nanocrystalline Ti-Cu alloy as a new orthopedic material." Colloids and Surfaces B: Biointerfaces 2020, 189 110889, DOI: 10.1016/j.colsurfb.2020.110889.

5. Javadhesari, S. M.; Alipour, S.; Akbarpour, M. R. Biocompatibility, osseointegration, antibacterial and mechanical properties of nanocrystalline Ti-Cu alloy as a new orthopedic material. Colloids and Surfaces B: Biointerfaces 2020, 189, 110889, https://doi.org/10.33263/BRIAC95.340344.

6. Ohtani, H.; Ishida, K. A thermodynamic study of the phase equilibria in the Bi-Sn-Sb system. Journal of electronic materials 1994, 23(8), 747-755.

7. Shrivastava, S.; Bera, T.; Roy, A.; Singh, G.; Ramachandrarao, P.; Dash, D. Characterization of enhanced antibacterial effects of novel silver nanoparticles. Nanotechnology 2007, 18(22), 225103, https://doi.org/10.1088/0957-4484/18/22/225103.

8. Teixeira, A. B. V.; de Castro, D. T.; Schiavon, M. A.; Dos Reis, A. C. Cytotoxicity and release ions of endodontic sealers incorporated with a silver and vanadium base nanomaterial. Odontology 2020, 1-8, https://doi.org/10.1007/s10266-020-00507-x.

9. Liu, S.; Deng, L.; Guo, W.; Zhang, C.; Liu, X.; Luo, J. Bulk Nanostructured Materials Design for FractureResistant Lithium Metal Anodes. Advanced Materials 2019, 31(15), 1807585, https://doi.org/10.1002/adma.201807585.

10. Yu, C.; Zhang, X.; Leng, M.; Shaga, A.; Liu, D.; Chen, F.;Wang, C. Preparation and thermoelectric properties of inhomogeneous bismuth telluride alloyed nanorods. Journal of alloys and compounds 2013, 570, 86-93, https://doi.org/10.1016/j.jallcom.2013.03.167.

11. Ayaad, D. M., Abdelaal, M. Y. A., Aboelkheir, A. M., \& Abdelghany, A. M. Performance enhancement of chitosan filled silver vanadate nano-rods. Journal of Inorganic and Organometallic Polymers and Materials 2019, 29(3), 901-907, https://doi.org/10.1007/s10904-018-01064-1.

12. Mustapha, S.; Ndamitso, M. M.; Abdulkareem, A. S.; Tijani, J. O.; Shuaib, D. T.; Mohammed, A. K.; Sumaila, A. Comparative study of crystallite size using Williamson-Hall and Debye-Scherrer plots for ZnO nanoparticles. Advances in Natural Sciences: Nanoscience and Nanotechnology 2019, 10(4), 045013, https://doi.org/10.1088/2043-6254/ab52f7.

13. Nath, D.; Singh, F.; Das, R. X-ray diffraction analysis by Williamson-Hall, Halder-Wagner and size-strain plot methods of CdSe nanoparticles-a comparative study. Materials Chemistry and Physics 2020, 239, 122021, https://doi.org/10.1016/j.matchemphys.2019.122021.

14. Gumaan, M. S.; Shalaby, R. M.; Yousef, M. K. M.; Ali, E. A.; Abdel-Hady, E. E. Nickel effects on the structural and some physical properties of the eutectic Sn-Ag lead-free solder alloy. Soldering \& Surface Mount Technology 2019, https://doi.org/10.1108/SSMT-03-2018-0009.

15. Shalaby, R. M.; Kamal, M.; Ali, E. A. M.; Gumaan, M. S. Design and properties of new lead-free solder joints using $\quad \mathrm{Sn}-3.5 \quad \mathrm{Ag}-\mathrm{Cu} \quad$ solder. Silicon $2018, \quad$ 10(5), https://doi.org/10.1016/j.ejbas.2018.05.003.

16. Abdelghany, A. M.; Menazea, A. A.; Ismail, A. M. Synthesis, characterization and antimicrobial activity of Chitosan/Polyvinyl Alcohol blend doped with Hibiscus Sabdariffa L. extract. Journal of Molecular Structure 2019, 1197, 603-60, https://doi.org/10.1016/j.molstruc.2019.07.089.

17. Meikhail, M. S.; Abdelghany, A. M.; Awad, W. M. Role of CdSe quantum dots in the structure and antibacterial activity of chitosan/poly $\varepsilon$-caprolactone thin films. Egyptian journal of basic and applied sciences 2018, 5(2), 138-144, https://doi.org/10.1016/j.ejbas.2018.05.003.

18. Mamatha, S. V.; Bhat, M.; Sagar, B. K.; Meenakshi, S. K. Synthesis, characterization, crystal structure biological activity of 4-\{2-[5-(4-fluoro-phenyl)-[1, 3, 4] oxadiazol-2-ylsulfanyl]-ethyl $\}$ - 


morpholine. Journal of $\quad$ Molecular $\quad$ Structure $\quad \mathbf{2 0 1 9}, \quad 1196, \quad$ 186-193.
https://doi.org/10.1016/j.molstruc.2019.06.065.

19. Kafashan, H. X-ray diffraction line profile analysis of undoped and Se-doped SnS thin films using Scherrer's, Williamson-Hall and size-strain plot methods. Journal of Electronic Materials 2019, 48(2), 1294-1309, https://doi.org/10.1007/s11664-018-6791-7.

20. Feijoo, I.; Cabeza, M.; Merino, P.; Pena, G.; Pérez, M. C.; Cruz, S.; Rey, P. Estimation of crystallite size and lattice strain in nano-sized $\mathrm{TiC}$ particle-reinforced 6005A aluminium alloy from X-ray diffraction line broadening. Powder Technology 2019, 343, 19-28, https://doi.org/10.1016/j.powtec.2018.11.010.

21. Ozdogan, A., \& Yesil Duymus, Z. Investigating the effect of different surface treatments on vickers hardness and flexural strength of zirconium and lithium disilicate ceramics. Journal of Prosthodontics 2020, 29(2), 129-135, https://doi.org/10.1111/jopr.12939. 